\title{
Embarrassment, Shame, and Reassurance: Emotion and Young People's Access to Online Sexual Health Information
}

\author{
Andrea Waling $^{1}$ (D) Adrian Farrugia ${ }^{1,2}$ (D) Suzanne Fraser ${ }^{1,3}(\mathbb{D}$ \\ Accepted: 12 November 2021 / Published online: 10 January 2022 \\ (C) The Author(s), under exclusive licence to Springer Science+Business Media, LLC, part of Springer Nature 2021
}

\begin{abstract}
Introduction Research suggests that embarrassment and shame are significant barriers to young people's access to sexual health information. In this article, we analyse the relationship between emotion and young people's engagement with online sexual health information.

Methods Drawing on the work of Ahmed on the performativity of emotion and Probyn's theorisation of shame, we analyse interviews conducted in 2020 with 37 young people in Australia on sources of sexual health information.

Results Based on themes emerging from the data, our analysis considers the role of embarrassment and shame in shaping young people's access to sexual health information, the sources they seek, and the forms of information provision they prefer. Overall, we find that shame, embarrassment, and judgement shape our participants' access to sexual health information in four key ways: (1) by enacting suitable sources of information; (2) by propelling curiosity in different directions; (3) by constituting 'normal' bodies, sexuality, and sexual health; and (4) by constituting desired forms of communication.

Conclusions As part of these dynamics, our participants use a range of strategies to avoid potential embarrassment or judgement when seeking sexual health information. The article concludes by exploring the implications of these practices and dynamics.

Policy Implications Our analysis suggests the need for research, policy, and public health initiatives that are open to the multiple effects of emotion, including those traditionally thought of as negative, and their role in materialising encounters with sexual health information.
\end{abstract}

Keywords Sexual health information $\cdot$ Young people $\cdot$ Shame $\cdot$ Relationships and sexuality education $\cdot$ Internet

\section{Introduction}

Public health and policy responses to youth sexuality and young people's sexual health often operate with an assumption that both are intrinsically shameful and embarrassing topics (Fallon, 2013; Holt et al., 2010; Litras et al., 2015). Shame is commonly understood as a response to stigma and

Andrea Waling

a.waling@latrobe.edu.au

1 Australian Research Centre in Sex, Health and Society, School of Psychology and Public Health, La Trobe University, Building NR6, Bundoora, Melbourne, VIC 3086, Australia

2 National Drug Research Institute, Curtin University, Melbourne, Australia

3 Centre for Social Research in Health, University of New South Wales, Sydney, Australia related concerns about being judged by others (Fallon, 2013; Gilbert, 1998; Probyn, 2004) and is routinely associated with other negative emotions such as embarrassment, guilt, and humiliation (Broucek, 1991). Young people in particular may experience high levels of shame and embarrassment regarding sexual health matters, with these experiences thought to prevent their access to high quality reliable sexual health information (Patterson et al., 2019). In this article, we draw on in-depth qualitative interviews conducted in 2020 with 37 young people in Australia to analyse how shame, embarrassment, and emotion more generally shape their access to sexual health information. In contrast to public health literature on emotion and young people's access to sexual health information, we do not approach shame and embarrassment solely as impediments or hurdles to accessing reliable information. Rather, we draw on Ahmed's (2004) theorisation of the performativity of emotions and Probyn's (2005) account of the multiplicity of shame. Drawing these 
resources together enables an analysis of the multiple effects of shame and embarrassment, emphasising that while they can limit access to sexual health information, this is not their only effect. Identifying four primary themes in our data, we argue that emotion, specifically shame and embarrassment, shape our participants' access to sexual health information in four key ways: (1) by enacting suitable sources of information; (2) by propelling curiosity in different directions; (3) by constituting 'normal' sexuality and sexual health; and (4) by constituting desired forms of communication. Drawing these dynamics together, we argue that shame and embarrassment should not be approached simply as hurdles to overcome in efforts to improve access to sexual health information but as resources that offer broader insights into the role of emotion in shaping understandings and experiences of sexual health and sexual life more broadly. These findings then form the basis for a series of recommendations we make to improve engagement with young people seeking sexual health information.

\section{Literature Review}

Shame and embarrassment routinely feature in research analysing young people's use of sexual health materials and services. For example, public health research on young people's use of sexual health clinics and community centres notes concerns about being identified accessing sexual health information on issues such as emergency contraception (Cassidy et al., 2014; Fallon, 2013; Lindberg et al., 2016). Experiences of shame have also been noted to be a key barrier to young people accessing testing and treatment for a range of matters such as sexually transmissible infections and human immunodeficiency virus and human papillomavirus screenings and vaccinations (Fortenberry, 2004; Fortenberry et al., 2002; Waller et al., 2007). Importantly, shame is thought to reduce testing and treatment for sexually transmissible infections, human immunodeficiency virus (Holt et al., 2010; Sayles et al., 2009), and cervical cancer screenings and vaccinations for human papillomavirus (McBride et al., 2020; Waller et al., 2007).

Feelings of embarrassment and shame and concerns about the judgement of others, that may surround the delivery and reception of sexual health information, have also been noted in studies of young people and their school-based relationships and sexuality education experiences (Leahy, 2014; Shoveller \& Johnson, 2006). Research suggests that embarrassment and discomfort experienced by teachers and students alike often negatively affect experiences of the curriculum (Pound et al., 2016; Waling et al., 2020a). In classrooms, shame not only shapes how young people engage with relationships and sexuality education but can also impede teachers, whose discomfort and embarrassment can mean they struggle with the material (Khan et al., 2020). Health providers such as general practitioners have also noted the difficulty in initiating conversations with young people about sexual health (Jarrett et al., 2011; Roberts et al., 2013). The shame and embarrassment that surround youth sexual health matters are often attributed to broader moral panics and cultural discomforts about young people, their changing bodies, and their sexuality. Importantly, such concerns include assumptions that teaching young people about sexual health and well-being will cause or encourage them to have sex (Angelides, 2019; Tupper, 2014; Waling et al., 2020b). Regardless of these concerns, many young people do learn about sex and sexuality outside of school and familial settings and some do become sexually active before reaching adulthood (Lim et al., 2014; Litras et al., 2015; Magee et al., 2012).

One such resource that young people are increasingly turning to for sexual health information is the Internet, which is considered easily accessible, confidential, and diverse in the range of information it provides (e.g. Baker et al., 2020; Dolcini et al., 2015; Lim et al., 2014; Litras et al., 2015; Patterson et al., 2019; Simon \& Danebeck, 2013). In an Australian national survey of secondary students on their sexual health and well-being conducted in 2018, the Internet was noted as a major source of sexual health information for young people but not as trusted as health providers (Fisher et al., 2019a). As the Internet provides access to confidential information, it can be more appealing and readily available than other sources such as health practitioners (Lim et al., 2014; Meldrum et al., 2015; Rawson \& Liamputtong, 2010). Research has also found that formal health websites, rather than social media websites, are key sources of health information for young people (Byron et al., 2013; Flanders et al., 2020; Patterson et al., 2019). Confidentiality has been noted as a major concern for young people, in that they fear using social media may result in exposure as accessing the information on sexual health (Patterson et al., 2019; Rawson \& Liamputtong, 2010; Waling et al., 2020c). However, recent research suggests online sources such as Reddit are emerging as key places for seeking sexual health information. Importantly, Reddit enables a high degree of anonymity not necessarily afforded by other social networking sites such as Facebook, Twitter, and Instagram. It also allows for asynchronous dialogue with others who may have similar experiences. Some research has also touched on the emotional underpinnings of the delivery of sexual health information. Importantly for our research, finding sexual health material that contains relatable lived experiences is particularly significant for gender and sexually diverse young people (Byron et al., 2013; Litras et al., 2015).

Public health research has noted the Internet is increasingly becoming an avenue of choice for young people to seek out sexual health information (Lim et al., 2014; Fisher 
et al., 2019a; Patterson et al., 2019). As such, a better understanding of what information they are looking for and why is vital to better support sexual health information delivery and the sexual and reproductive health and well-being of young people. This includes not only a consideration of the accessibility or practical aspects of accessing information online (Patterson et al., 2019) but also the emotions (Byron et al., 2013; Litras et al., 2015; Flanders et al., 2020) that can inform why young people choose certain sources over others. In this article, we build on this scholarship in two ways: (1) by analysing in depth what guides or informs young people's search for information and how feelings shape their engagement and what kinds of information they seek and (2) by analysing shame, embarrassment, and emotion more broadly, not just has hurdles to sexual health information but as complex forces with multiple effects for young people and their access to sexual health information.

\section{Approach}

Developed over at least 4 decades of scholarship, the sociology of emotion is a diverse field offering an array of approaches to understand the role of emotion in social life (for a review see Bericat, 2016). Shared within this field of research is an understanding that emotions form part of the fabric of everyday life and an emphasis on the social nature of human emotions and the emotional nature of all social phenomena (Bericat, 2016). Given this body of work and the, at times, conflicting approaches mobilised within it, how should we approach the relationship between emotion and young people's access to sexual health information?

In this analysis, we work with cultural theorist Ahmed's (2004) theorisation of emotions as productive of bodily and collective boundaries. Ahmed's work is useful for our analysis firstly because she offers a distinctly performative account of emotions that emphasises their role in constituting subjects and collectivities. This approach avoids the limitations of common-sense understandings of emotion that position it as either located in and emanating out from individual subjects or as distinct from individuals and moving inwards from society. As she argues, both these approaches reify emotion as either the origin or product of other phenomena. Second, her approach avoids the pitfalls of individualising accounts of emotions that suggest they must be removed from debates about sexual health in favour of objective, 'evidence-based' initiatives (for a related argument about obesity discourse, see Fraser et al., 2010). While superficially appealing, these arguments are naive to the intimately political nature of all evidence and the role that much 'evidence-based' sexuality education plays in homogenising and effacing personal experiences (Lamb, 2013).
In contrast to these accounts, Ahmed (2004) approaches emotion as a force that emerges between subjects, and between subjects and society, a force that acts to produce and define the boundaries of subjects and collectivities, that is, as performative of them. Ahmed illustrates this argument through a discussion of hate and white nationalism:

Hate may generate the other as the object of hate insofar as it repeats associations that already read the bodies of others as being hateful. Indeed, the loop of the performative works powerfully: in reading the other as being hateful, the subject is filled up with hate, as a sign of the truth of the reading. (2004, p.32)

While our research concern is far removed from the politics of white nationalism and hate, the process Ahmed describes nonetheless has relevance for our analysis of emotion and online sexual health information. The performative approach to emotion Ahmed offers enables an analysis of the ways in which emotions performatively constitute subjects and collectivities of sexual health, drawing into focus the role sexual health information provision has in constituting some of the experiences and subjects it is usually understood to address.

Given the prevalence of shame and embarrassment in the young participants' discussions of how and why they access online sexual health information, we also draw on conceptual resources offered by cultural theorist Probyn's (2005). Following Silvan Tomkins, shame for Probyn is,

an ambiguous state of feeling, emotion, and affect.

[This] gestures to shame as the fine line or border between moving forward into more interest or falling back into humiliation. (xii)

Importantly, Probyn's account of shame does not position the experience or manifestation of shame as intrinsically negative. Rather, Probyn emphasises the performative or productive and heterogeneous power of shame. As Ahmed argues in relation to emotion more generally, Probyn theorises shame as a force that emerges from the relations between phenomena and is, therefore, productive of the subjects and other entities that are usually understood as its origin:

Shame cannot be conceived of as an external object that could be dispassionately described, nor is it a purely personal feeling. Shame is subjective in the strong sense of bringing into being an entity or an idea through the specific explosion of mind, body, place, and history. (148)

In this way, our approach contrasts with other literature on shame and sexual health that tends to position this phenomenon as having singular and predictable effects: impeding access to sexual health information. Rather, we 
approach emotion as a complex force that exists between rather than within subjects and relationships and generates effects in multiple directions. We do not focus on multiplicity to underemphasise the well-documented negative effects of shame and embarrassment but to offer a fuller account of their effects. As we will explore further, rather than necessarily propelling our participants into humiliation, shame and embarrassment move their interest in sexual health in different directions. While remaining critical of discourses that constitute youth sexuality as an intrinsically shameful and embarrassing issue, we seek to analyse the productive or performative effects of these emotions on young people's access to sexual health information. Reflecting on this, our key question is 'what do shame, embarrassment, and emotion more generally do for young people's access to online sexual health information?'.

\section{Method $^{1}$}

This article analyses 37 semi-structured interviews conducted in Australia in 2020 with young people aged between 18 and 21. As interviews were conducted during the outbreak of coronavirus (COVID-19) in Australia, audio/video conferencing, phone calls, and instant messaging were used in lieu of face-to-face interviews.

\section{Recruitment and Data Collection}

Recruitment was conducted using a database of contacts developed for a national sexual health survey of secondary students in 2018 (Fisher et al., 2019b). All participants in the survey were between the ages of 14 and 18 . Hence, in this subsequent qualitative study (Farrugia et al., 2021; Fraser et al., 2021; Waling et al., 2020c), participants were aged between 18 and 21. All survey participants were Australian citizens or permanent residents, meaning all participants in the qualitative study were also Australian citizens or permanent residents ${ }^{2}$. Participants were invited to respond to an email about the project and were then screened to confirm eligibility. Thirty-two young people were recruited, of whom 15 were women (heterosexual and lesbian, bisexual, and pansexual). A special call for young men and trans and gender-diverse people on social media was conducted, with five more participants recruited in this way.

\footnotetext{
1 This method section is adapted from other articles published by the authors (Farrugia et al., 2021; Fraser et al., 2021; Waling et al., 2020c).

2 The inclusion criterion of Australian citizenship or permanent residency status was determined by the approach taken in the national sexual health survey of secondary students (Fisher et al., 2019a), from which the study being reported on here drew its participants.
}

Interviews were conducted between March and June 2020. Prior to the interview, participants were given an information statement explaining the project. Consent was provided through written means or audio-recorded before the interview. Interview topics included preferred sources of sexual health information, experiences of relationships and sexuality education in schools, why and how certain sources were chosen over others, how credibility and trustworthiness were assessed or determined, and what measures might be effective in developing trust and improving access to reliable sexual health information. The interviews were based on a broad understanding of sexual health that encompasses a range of knowledge and practices across a spectrum of physical, sexual, social, and emotional well-being (World Health Organisation, 2006). As 'sexual health' can have an array of meanings, follow-up questions were asked if participants did not mention particular topics. These included issues of consent, relationships, pleasure, and diverse genders and sexualities. Audio and video conferencing interviews were professionally transcribed. Instant messaging is conducted in a text format and thus did not require transcription. Participants were offered a $\$ 25$ gift voucher as reimbursement for their time and Internet costs. All participants were offered the option to review their transcripts, a process known as member-checking (Birt et al., 2016). All identifying details were removed from the transcripts and all participants were assigned a pseudonym. Terms used to describe gender are based on participant self-descriptions, and we use the phrase 'young people' throughout to be inclusive of diverse gender identities. Interviews continued until data saturation was reached, that is, the point at which no new insights were generated (Saunders et al., 2018).

\section{Note on Effects of Coronavirus (COVID-19) on Research}

Interviews conducted during the coronavirus (COVID-19) pandemic involved measures that produced both limitations and benefits. While the different functionalities of the technologies likely shaped how the interviews unfolded in ways that differ from the effects of face-to-face interviewing, the approach allowed us to be highly flexible in complying with the coronavirus (COVID-19) restrictions and adapting to the contextual constraints of our participants. For example, most young people did not have access to private spaces for aural or video-chat interviews (four out of five were living with their parents at the time of the interview). As a result, about half opted for an instant messaging interview as this enabled a degree of privacy and freedom in responding. While these data collection methods had several benefits, they also posed some challenges. For example, unlike inperson interviews, the instant messaging medium does not communicate important social cues such as vocal inflexion, 
body language, and facial expression. Various strategies were used to monitor participant wellbeing during instant message interviews. Interviewers, for example, at times asked direct questions about well-being, used emojis (textbased images or keystrokes of faces to denote an emotion) to communicate feelings, or assessed participant use of emojis. Additionally, some participants indicated that the presence of family members caused them to postpone answering interview questions. Despite these challenges, these methods proved successful in supporting young people to talk openly about their sexuality, their sexual health information-seeking practices, and their sexual health more broadly. Some of the benefits included enabling young people to participate without travelling, particularly important for those with limited resources or physical mobility restrictions. Offering a variety of interview options allowed participants to nominate their preferred option, reducing potential reticence during the interview. Additionally, reflecting previous research comparing interview methods (e.g. Barratt, 2012; Shapka et al., 2016), we did not note significant differences in the quality of the data generated by these methods.

\section{Participants}

Table 1 provides an overview of the demographic characteristics of participants.

Almost half the participants were young men (46\%) followed by young women (41\%) and trans and gender-diverse young people (11\%). Just over half of participants identified as heterosexual (59\%), while the remaining $41 \%$ identified as lesbian, gay, bisexual, or pansexual. About half of the participants identified as Anglo-Celtic (51\%) and about twothirds were born in Australia (68\%). Just over half were in a relationship (54\%), and the majority identified as being monogamous or in the case of single people, would seek monogamous relationships (86\%). Nearly half of the participants lived in the state of Victoria (46\%) and in outer suburban areas (49\%). At the time of interviewing, most were living with their parents (81\%) which, for some, were due to the coronavirus (COVID-19) lockdown restrictions. Over $81 \%$ were also undertaking postsecondary schooling such as university or technical and further education (TAFE) at the time of being interviewed.

Importantly for our project, some aspects of our participant profile were unusual. Most participants were university students, which means they had relatively high levels of education. Many may have had access to sexual health information through resources such as university sexual health weeks and on-site campus services. Additionally, half of the participants identified as gay, lesbian, bisexual, or pansexual. These sexual orientations are often not represented in relationships and sexuality education curriculum. In addition, participants may have been compelled to seek
Table 1 Demographic characteristics of participants $(N=37)$

\begin{tabular}{|c|c|c|}
\hline & $N$ & $\% *$ \\
\hline \multicolumn{3}{|l|}{ Age } \\
\hline 19 & 15 & $41 \%$ \\
\hline 18 & 13 & $35 \%$ \\
\hline 20 & 7 & $19 \%$ \\
\hline 21 & 2 & $5 \%$ \\
\hline \multicolumn{3}{|l|}{ Assigned sex at birth } \\
\hline Male & 19 & $51 \%$ \\
\hline Female & 18 & $49 \%$ \\
\hline \multicolumn{3}{|l|}{ Completed education } \\
\hline Secondary school & 33 & $89 \%$ \\
\hline Primary school & 2 & $5 \%$ \\
\hline Bachelor's degree & 1 & $3 \%$ \\
\hline TAFE & 1 & $3 \%$ \\
\hline \multicolumn{3}{|l|}{ Country of birth } \\
\hline Australia & 25 & $68 \%$ \\
\hline India & 2 & $5 \%$ \\
\hline Malaysia & 2 & $5 \%$ \\
\hline South Africa & 2 & $5 \%$ \\
\hline Bosnia and Herzegovina & 1 & $3 \%$ \\
\hline Indonesia & 1 & $3 \%$ \\
\hline Kyrgyzstan & 1 & $3 \%$ \\
\hline New Zealand & 1 & $3 \%$ \\
\hline Singapore & 1 & $3 \%$ \\
\hline United Kingdom & 1 & $3 \%$ \\
\hline \multicolumn{3}{|l|}{ Employment/study status } \\
\hline University student & 30 & $81 \%$ \\
\hline High school student & 4 & $11 \%$ \\
\hline Unemployed & 2 & $5 \%$ \\
\hline Employed & 1 & $3 \%$ \\
\hline \multicolumn{3}{|l|}{ Ethnicity** } \\
\hline Anglo-Celtic Australian & 19 & $51 \%$ \\
\hline Northwest European & 4 & $11 \%$ \\
\hline Southern and Central Asian & 4 & $11 \%$ \\
\hline Southern and Eastern European & 3 & $8 \%$ \\
\hline Southern and East African & 2 & $5 \%$ \\
\hline Australian Aboriginal & 1 & $3 \%$ \\
\hline Eastern European & 1 & $3 \%$ \\
\hline Maori & 1 & $3 \%$ \\
\hline Maritime Southeast Asian & 1 & $3 \%$ \\
\hline Northeast Asian & 1 & $3 \%$ \\
\hline \multicolumn{3}{|l|}{ Housing status } \\
\hline With parents & 30 & $81 \%$ \\
\hline Shared accommodation & 2 & $5 \%$ \\
\hline University residence & 2 & $5 \%$ \\
\hline With partner & 2 & $5 \%$ \\
\hline Sole resident & 1 & $3 \%$ \\
\hline \multicolumn{3}{|l|}{ Relationship status } \\
\hline Relationship & 20 & $54 \%$ \\
\hline Single & 15 & $41 \%$ \\
\hline Casual dating & 2 & $5 \%$ \\
\hline
\end{tabular}


Table 1 (continued)

\begin{tabular}{|c|c|c|}
\hline & $N$ & $\% *$ \\
\hline \multicolumn{3}{|l|}{ Relationship style } \\
\hline Monogamous & 32 & $86 \%$ \\
\hline Either & 4 & $11 \%$ \\
\hline Polyamorous & 1 & $3 \%$ \\
\hline \multicolumn{3}{|l|}{ Religion } \\
\hline Not religious & 21 & $57 \%$ \\
\hline Christian & 5 & $14 \%$ \\
\hline Catholic & 3 & $8 \%$ \\
\hline Agonistic & 2 & $5 \%$ \\
\hline Hindu & 2 & $5 \%$ \\
\hline Atheist & 1 & $3 \%$ \\
\hline Buddhist & 1 & $3 \%$ \\
\hline Orthodox Christian & 1 & $3 \%$ \\
\hline Pagan & 1 & $3 \%$ \\
\hline \multicolumn{3}{|l|}{ Residential location } \\
\hline Outer suburban & 18 & $49 \%$ \\
\hline Capital city/inner suburban & 9 & $24 \%$ \\
\hline Regional & 8 & $22 \%$ \\
\hline Rural & 2 & $5 \%$ \\
\hline \multicolumn{3}{|l|}{ Secondary school type $* * *$} \\
\hline Government schools & 20 & $54 \%$ \\
\hline Other private schools & 11 & $30 \%$ \\
\hline Religious-based schools & 6 & $16 \%$ \\
\hline \multicolumn{3}{|c|}{ Self-identified gender identity $* * * *$} \\
\hline Man & 17 & $46 \%$ \\
\hline Woman & 15 & $41 \%$ \\
\hline Trans woman & 2 & $5 \%$ \\
\hline Genderqueer & 1 & $3 \%$ \\
\hline Nonbinary & 1 & $3 \%$ \\
\hline Trans man & 1 & $3 \%$ \\
\hline \multicolumn{3}{|c|}{ Self-identified sexual orientation $* * * *$} \\
\hline Heterosexual or straight & 22 & $59 \%$ \\
\hline Bisexual & 8 & $22 \%$ \\
\hline Gay or lesbian & 5 & $14 \%$ \\
\hline Pansexual & 2 & $5 \%$ \\
\hline \multicolumn{3}{|l|}{ State/territory } \\
\hline Victoria (VIC) & 17 & $46 \%$ \\
\hline New South Wales (NSW) & 10 & $27 \%$ \\
\hline Queensland (QLD) & 5 & $14 \%$ \\
\hline South Australia (SA) & 3 & $8 \%$ \\
\hline Tasmania (TAS) & 1 & $3 \%$ \\
\hline Western Australia (WA) & 1 & $3 \%$ \\
\hline
\end{tabular}

* Percentages have been rounded up to the nearest whole percentage and may not add up to $100 \%$ as a result

${ }^{* *}$ Ethnicity is reported following the Australian Standard Classification of Cultural and Ethnic Groups, developed by the Australian Bureau of Statistics. Cultural and ethnic background was classified according to a combination of self-reported group identification with cultural or ethnic groups, participants' birthplace and their parents' birthplaces

${ }^{* * *}$ School types are reported based on participant descriptions

**** Gender and sexual orientation are reported based on participants' self-selected terms out information relevant to their lived experiences of gender and sexuality diversity, thus acquiring skillsets to achieve this. In sum, the specificities of our dataset - for example, education levels and range of gender identities - should be considered when assessing the potential relevance of our analysis for other research.

Ethics approval for this project was granted by the $\mathrm{La}$ Trobe University (HEC20004).

\section{Analysis}

Data analysis was conducted using the qualitative method outlined by Braun and Clarke (2006). The first step was familiarisation with the data by reading the transcripts and post-interview notes. A coding schedule was developed in reference to the aims of the project, relevant literature, and the contents of the interviews. This schedule was crosschecked between authors 1 and 3 prior to coding, using the constant comparison method. This involves cross-checking emergent themes with analysed transcripts, as well as paying attention to theoretical saturation (Saunders et al., 2018). Top-level codes included 'sources of sexual health information', 'sex education in schools', 'sexual health knowledge', 'trust in sexual health information', and 'examples of sexual health resources'. The data for this paper were drawn from all these codes. Themes emerging from these codes were explored, agreed upon by the authors to ensure their relevancy to the research questions, and then defined and analysed using a theoretical triangulation method that works with multiple theories to guide the research collection and analysis (Flick, 2011; see Waling et al., 2020c for an overview of themes in the dataset). Of course, young people will experience a complex array of emotions when accessing sexual health information. While we focus on shame here, previous articles stemming from this research have analysed young people's trust of online sexual health information (Farrugia et al., 2021) and the forms of citizenship such information makes available (Fraser et al., 2021).

\section{Findings}

In this article, we focus specifically on how shame and embarrassment shape young people's access to and assessment $^{3}$ of sexual health information. Specifically, we analyse how these feelings and concerns about experiencing judgement shaped young people's access to sexual health information in multiple ways. Given these dynamics, we argue that young people value avenues to sexual health information that

\footnotetext{
3 Audio and video chat interviews have been lightly edited for clarity.
} 
allow not only confidentiality, anonymity, and privacy but also reassurance, care, and support.

\section{Enacting Suitable Sources of Information}

Given research suggests young people prefer confidential access to sexual health information (Byron et al., 2013; Patterson et al., 2019; Rawson \& Liamputtong, 2010), it is perhaps not surprising that our participants valued privacy and anonymity. Apart from fleeting attention to feelings of embarrassment; however, research to date has not analysed in depth the significance of confidentiality and privacy for young people. As we will argue, part of the significance of these emotions is their role in actively constituting suitable sources of sexual health information. For example, in our interviews, the importance of confidentiality and privacy emerge most commonly in discussions of turning to parents, friends and general practitioners for sexual health advice:

Mark (man, 19, heterosexual, IM): I think it might come down to illogical embarrassment, in terms of my parents I just don't like telling them stuff which I think is too personal as I'm scared they'll gossip among their friends, and I think that feeling carries over to some degree with GPs and friends.

Gillian (woman, 19, heterosexual, IM): I would talk to my mother (single parent family) about my thoughts about sex like, almost philosophically, but again probably not the specifics. When talking about other people's sex lives she has often expressed disgust. I know she might not do that to me but it is a bit of a deterrent.

Here, embarrassment and disgust work to materialise boundaries between Mark and Gillian and their parents as sources of sexual health information. Importantly, cultural anxieties about teen sexuality have been identified as limiting young people and parents' ability to speak openly about it (Ringrose, 2016). Indeed, feelings of shame and embarrassment shape communication even for those participants who considered their parents potential sources of sexual health information:

Ted (man, 19, heterosexual, audio chat): No, I didn't ever go to my parents. I had a better relationship with my mum than I did with my dad, so going to my dad for questions wasn't really an option for me. And I had, like, the talk with my mum and it popped up a couple of times as well. Mum's very comfortable with talking about sexuality and stuff like that. So yeah, she was adamant that she wanted to have the talk no matter the partner that I was with. So the option was always there if I did need to talk to mum about it but it just never came up really.
Interviewer: So it's that case of, she's there and you knew you could go to her but...

Ted: I'd rather not, yeah.

Viraj (man, 19, heterosexual, IM): I do worry a bit about being judged, and I do feel embarrassed talking to them [parents] about this. However, it is not due to anything they have said, done, or enforced upon me they are quite open regarding this topic and encourage me to talk to them if I ever have any questions. The embarrassment comes more from within myself, probably due to my own inhibitions.

Both Ted and Viraj note that their parents were available and accessible, yet this does not mitigate the role of embarrassment in limiting communication between them. This discomfort is echoed in experiences of formal relationships and sexuality education, in that these young people appear highly cognisant of teachers' discomfort presenting the course material:

Jennifer (woman, heterosexual, 19, video chat): Yeah, we had sex ed, but we always had male teachers who just felt $[. .$.$] awkward about talking about it. I remem-$ ber back in Year 8 when they were teaching us about periods, and I hadn't had my period yet. So I was actually like wanting to learn, and he [the male teacher] was like 'oh periods, you know all about that, we don't need to do that.' They'd still feel awkward talking about it when it shouldn't be.

Edward (trans man, 19, lesbian, audio chat): It's really embarrassing in a school setting to even talk about it in the first place, and with your teacher who's like so much older than you. Like, it's all right when you're just talking about it between your mates, but when you've got a teacher in front like doing the teaching it's a bit [of a] 'oh I don't want to be a part of this' type of situation.

In a process similar to that which constituted parents as inappropriate avenues of information, embarrassment and discomfort here materialise a boundary between young people and teachers: teachers are sources of sexual health information but ones ill-suited to the needs of our participants. Of course, Jennifer's account also highlights the intimately gendering character of the emotions involved in sexual health information provision: shame and embarrassment act to reproduce gender in traditional ways with the feminine sidelined and treated as marginal to the main task (Fields, 2008).

Further highlighting the significance of gender, many of the young women we interviewed express concern about being judged for accessing sexual health information, especially where it might reveal their own sexual practices: 
Hailey (woman, 19, heterosexual, audio chat): I've been bullied [by friends] for being considered to be a slut even though I haven't had [...] that many sexual partners.

Lucy (woman, 20, bisexual, audio chat): I think that at least with like my parents they still sort of see me as [...] too young to be looking into that sort of thing.

Echoing other research (Cassidy et al., 2014; Fallon, 2013; Lindberg et al., 2016), Hailey and Lucy's comments suggest that young women in particular experience a range of barriers to accessing sexual health-related support. As we will argue in the next section, however, shame, embarrassment, and a fear of judgment do not solely act as barriers to sexual health information. Rather, these emotions operate to produce effects at both collective and individual levels - effects that constitute, in this instance, gendered subjects and collectivities of sexual health that preclude certain sources of information such as parents and teachers and thereby include others.

\section{Propelling Curiosity in New Directions}

As Probyn (2005) argues, shame is not a stable emotion with a singular and intrinsically negative effect. Rather, it has multiple effects and can act as a border between moving forward with renewed interest or falling back into humiliation (p. xii). Reflecting this dynamic, our participants' concerns about shame, embarrassment, and judgment did not so much block their access to sexual health information as propel it in different directions. Most commonly reported in our interviews were a series of strategies to anonymously access sexual health information:

Aarav (man, 18, straight, video chat): I would go online I think to get any sexual health information. [This is] because, I guess, in our culture it's not overly talked about at home or with your parents.

Aidan (man, 19, straight, IM): [discussing the internet as a preferred source] It's very easy to access, confidential and you can verify information by crossreferencing. Confidential is preferred over talking to friends I guess because I don't want them to know everything about my relationship/sexual health.

Here Aarav explains that while he can potentially go to his parents, his preference for the internet is related to cultural norms regarding discussions of sexual health. For Aidan, confidentiality is key to avoid sharing information about himself with others. Alongside discretion, access to a range of information is also central to many of the accounts offered by our participants and a key reason for preferring online information, as Ilana explains about her preference for the internet:
Ilana (woman, 18, lesbian, IM): It's pretty much anonymous and there's no real fear of judgement or anything + I feel as if there's a lot more variety of information on there than any one person could tell me Interviewer: And with the internet can you describe some of your experiences, have you found it particularly helpful in accessing the information that you need?

Ilana: Yeah, I find as a lesbian that there are quite a lot of LGBT+ [lesbian, gay, bisexual, trans, plus] oriented health/sex ed [education] resources - and to add on to the earlier question, I feel like none of my family or my GP [general practitioner] would be particularly helpful when it comes to non-heterosexual sexual health information.

Measures used to ensure confidentiality range from using mobile phones in private spaces, to using the "private browsing' option on phones so as not to record search history and even using two mobile phones to mitigate the potential of consequences of being 'found out' by family members.

Hailey: [I'd] probably do it on a, so you know how on Safari [web browser] from doing it on my phone you can do the, you can click on [the] private [setting] or deleting my browser history, things like that.

Jessica (woman, 18, bisexual, video chat): I know if I'm going to the GP [general practitioner] or if I'm going to see a partner, I leave my phone at home and take the other one with me so that they [her parents] can't track where I am.

Interviewer: So You Even Have Two Phones to EnsureJessica: Yeah but that wasn't like, I didn't go out and buy a new phone so I could do that. It was just like 'oh I got an upgrade, cool here's a phone that I can take with me' so I don't, you know, get into any major trouble or they [her parents] don't figure anything out sort of thing.

Hailey and Jessica operate in a context that positions sex and sexuality as shameful, taboo, and inappropriate for young people (Fallon, 2013) but does not block their interest in sexual health altogether. In this way and others, our participants' curiosity was pushed into different directions, resulting in the use of a range of strategies to ensure privacy.

\section{Care, Reassurance, and Support}

Alongside the shame and embarrassment that participants said shaped many practices of seeking sexual health information, they also express a desire for care, compassion, understanding, and reassurance as to the normality of their concerns, lives, and bodies. Indeed, the question 'am I normal?' flows through many of their inquiries: 
Mark (man, 19, heterosexual, IM): I think that's how I've felt towards reddit when I've used it, I felt a reassurance in people having the same opinions or questions/ issues as me.

Interviewer: Okay, so having access to people who might have similar experiences has been really useful for you? Mark: So I think it was more of a reassurance than what should have been a valid answer/ useful.

The reassurance Mark gained from finding that his opinions, questions, and concerns were shared with others forms part of a broader emotional dynamic that is the subject of this article. Here, the shame and embarrassment emerging from encounters with sexual health information operate to materialise and define the boundaries of 'normal' sexuality and sexual health:

Zander (man, 20, heterosexual, audio chat): With regards to sexual health and the male genitalia, I've definitely had to look up to make sure, to see if it is everything is normal.

Eve (woman, 18, bisexual, IM): [I researched] what a 'good' amount of washing/rinsing is [vaginal hygiene]. Jennifer: I had no idea like that nipples change shape, and I actually like was scared to engage in sexual conduct with anyone because I thought I was going to be shamed for my nipples [...]. I was looking up surgeries to go have normal nipples.

Participants describe asking many questions about the body, such as whether parts of their bodies look normal, the impact of hormonal and long-acting reversible contraception on the body, menstrual issues, and changes in genital appearance. Through this process of questioning and identifying information, a normal body and normal experience of sexuality and sexual health take shape. In this respect, rather than positioning shame about sexuality as only blocking access to information, our analysis suggests that shame is part of a dynamic that produces 'intensifications of feeling' (Ahmed, 2004) that define the boundaries of normal subjects (with normal sexual interests and practices) and normal objects (normal bodies, etc.). Shame and embarrassment are part of the process that produces bodily boundaries and their position (normal/abnormal) in sexual and social life. Beyond this, however, shame has other effects too. Most importantly for our analysis, shame and embarrassment are implicated in a preference for caring and reassuring sexual health information, generating a related investment in specific forms of communication.

\section{Communication}

While shame and embarrassment are implicated in the seeking of private and confidential avenues for accessing sexual health information, they also encourage relationally produced knowledge, that is, the opportunity to engage in dialogue, either synchronous or asynchronous, about sexual health (Flanders et al., 2020). Kayla, for example, explains that she likes online resources that allow for discussion.

Kayla (woman, 18, bisexual, IM): I think Reddit is helpful just for hearing a variety of different scenarios about people's experiences, related to birth control, sex and relationships. I enjoy the Flo app as it gives me curated feedback based on my own menstrual cycle, and also has anonymous discussions available between the users.

As suggested in the previous section, the young people in this study seek information that can provide a degree of support or care, highlighting that accessing sexual health information seeking cannot be reduced to fact seeking and is an emotionally charged and affective experience (Byron et al., 2013).

Hailey: Definitely using the forum base and, like, Reddit and Eve when I've had a specific question. Having people come back and answer it [the question] and be supportive [...is helpful]. That's why that Eve App is particularly good because it's supposed to be just for women so they [are mostly other] women on the App. [...] Being able to share their experience and give support is a lot better than, like, reading something on a medical page and just being like 'oh my God, I could have cancer.'

As a result, while the young people certainly looked for sources of sexual health information that were factual and provided accurate information (e.g. Farrugia et al., 2021; Fraser et al. 2021), they also describe seeking resources that enable them to discuss what they find in an encouraging and supportive manner:

Jake (man, 18, gay, IM): Yeah since I find subreddits like r/gaybros and r/askgaybros are pretty supportive and non-judgemental.

Stuart (man, 21, straight, IM): I've come across a few verified sexual health therapists/researchers on reddit who have given advice to people in similar situations like me and have found what they said to be quite helpful and touching.

This desire for nonjudgmental communication positions sources such as online forums or apps that allow for discussion of lived experience are particularly valuable.

When asked about how they would prefer to receive sexual health information, participants respond that a combination of a private and confidential resource that also allows for asynchronous or synchronous dialogue is the best: 
Abby (trans woman, 21, pansexual, video chat): I've found things like medical professional websites where they have, like, you email them questions. I haven't done it now, but it was quite helpful being able to get help without anxiety and with it being a specific, my specific issue.

Jessica: I would love to have a moderated sort of discussion or community board where people could, you know, really work through what's helped them but also have that be carefully looked through [by experts].

Here, Abby notes that while she prefers a website that enables confidential communication, she still values the possibility to engage with health professionals. Likewise, Jessica points to the value of a forum that allows for discussing individual experiences but is also carefully moderated. In this way, while shame and embarrassment enact hurdles to some potential sources of information such as parents and teachers; they are also implicated in materialising other effects too, in this case, new forms of communication, specifically private and confidential online dialogue conducted in a caring and encouraging register. As we have emphasised throughout this analysis then, shame and embarrassment should not be approached as if they only have one effect - as barriers to sexual health information - but as a force that shapes young people's encounters with sexual health in multiple ways, generating action in multiple directions.

\section{Discussion}

In this article, we have analysed how emotion, specifically shame and embarrassment, shape young people's access to and use of sexual health information. In contrast to much research that approaches shame and embarrassment purely as barriers or hurdles to information, we drew on Ahmed (2004) and Probyn's (2005) performative approaches to emotion to argue that shame and embarrassment are complex forces with multiple effects. As our analysis indicates, and reflecting other research in this area, at times shame and embarrassment did impede access to specific avenues of sexual health information. This occurred by constituting parents and teachers as inappropriate avenues for finding information on this controversial topic. Yet, given the centrality of digital technologies in contemporary life for many young people, it is no surprise that this dynamic did not stop their access to sexual health resources altogether. Rather, as we argue, their curiosity and interest were thrust in different directions - most obviously towards the Internet.

Given the multiple implications of shame and embarrassment for participants' access to and use of sexual health information, we do not solely ask how to ameliorate the influence of such emotions. Rather, we ask a broader ques- tion: what do shame, embarrassment, and emotion more generally do for young people's access to online sexual health information? In this sense, we approach these emotions not simply as problems to be solved but as resources (Probyn, 2005) that can offer insight into the role of emotion in young people's understandings of sexual health. As Ahmed argues,

Emotions are what move us. But emotions are also about attachments, about what connects us to this or that [...] What moves us, what makes us feel, is also that which holds us in place. (Ahmed, 2004, p.27 original emphasis).

In arguing that emotions both move and secure us, their effects cannot be readily assessed as wholly positive or negative. In our research, shame and embarrassment operated to materialise a series of movements and anchors. In materialising boundaries that constituted parents as inappropriate avenues for sexual health information, shame and embarrassment could be understood to pin down and limit how and where young people can access information and their relationships with their parents more generally. However, these young people were moved to access information in other ways and enacted strategies to ensure privacy and confidentiality. Yet, this has multiple effects, too, for example, it potentially reconstitutes youth sexuality as an embarrassing topic, only to be researched in private and certainly not suitable for open dialogue. Our participants' use of confidential online sexual health resources has multiple effects, too. Firstly, it was implicated in materialising caring and compassionate communication about sexual health. Yet, at the same time, the shame and embarrassment also worked to pin down a 'normal' account of bodies, sexual health, and sexual life that may marginalise young people who do not fit within its confines (Angelides, 2019; Fields, 2008). If emotions create both movement and stasis, we cannot simply jettison them from the discussion of youth sexual health or relationship and sexuality education initiatives. Indeed, it is very likely that emotion will always be an important force in constituting how sexual health is understood and experienced.

Given various international agencies (e.g. UNESCO, 2021) and Australian policies (Commonwealth of Australia, 2018) emphasise the importance of young people's access to sexual health information that supports their well-being; it is essential to consider the implications of our analysis for future sexuality and relationship education efforts. As we have argued, emotions such as shame do not have one linear effect on young people's engagement with sexual health information and this multiplicity is key to developing approaches that work with this dynamic productively.

Our analysis suggests that relationship and sexuality education strategies could directly, if carefully, acknowledge the embarrassment and discomfort often shaping discussions of these issues between different groups such as young people, 
parents, and teachers. Given the dynamics analysed here, our intention is not to suggest that this acknowledgement should be focussed purely on ameliorating these emotions but to engage with them not necessarily as a problem per se but a complexity that many people will negotiate as part of sexual and social life beyond education and health promotion efforts. Relatedly, funding and policy to support additional training of relevant health professionals to have productive, encouraging, and open conversations with young people about sexual health would be beneficial (Fraser et al., 2020; Jarrett et al., 2011; Roberts et al., 2013).

In responding to emotion and the need for reassurance and support, relationship and sexuality education strategies could emphasise the plethora of gender and sexual expressions and desires, as well as related concerns and potential risks. We argue that such an approach should not attempt to reassure young people by reinstating that certain experiences are 'normal', as this category necessarily constitutes an 'abnormal' other but to engage with the notion of normal and abnormal more directly. This is a focus on opening up such ideas and weakening their grip through a direct focus on multiplicity and the constantly changing character of sexual life such that the notion of normal and its relationship to shame and embarrassment become open to critical scrutiny.

We note the significance of sexual health resources that are confidential and private but also allow for young people to speak with others about their experiences. Further, our analysis indicates the importance of engaging with different forms of knowledge, for example, those stemming from peers' lived experience and those of relevant health professionals. This is particularly important for those whose experiences are positioned outside current norms or may not be adequately represented in current school-based relationships and sexuality education curriculum. Resources that combine professionally produced information with lived experience, asynchronous or synchronous modes of communication with others in a confidential manner (i.e. question and answer [QA] forums or discussion boards, instant chat) may be useful for young people navigating these issues. Importantly, our analysis indicates that to best support young people seeking sexual health information, such strategies should be developed within a supporting, open, reassuring, and caring discursive register that explicitly engages with difference.

\section{Conclusion}

Our analysis suggests the need for research, policy, and public health initiatives that are open to the multiple effects of emotion, including those traditionally thought of as negative, and their role in materialising encounters with sexual health information. Additionally, public health and policy efforts to provide young people with sexual health information need to be similarly attuned to emotion, not only to support young people and avoid what can be very negative effects of shame and embarrassment (which we do not wish to suggest are unimportant) or improve how responses resonate with their audiences but also to provide resources that young people can draw on to inform their understanding of emotion in their experiences of sexual health and sexual life more generally. More specifically, such resources may be most effective where they combine lived experience with professionally produced information and would ideally be available in both asynchronous or synchronous formats (recalling that our participants valued both). They would also maintain the anonymity and confidentiality of young people. By attending to emotions differently and communicating sexual health issues and information in new ways, these initiatives could remake the relationship between young people and sexual health in positive new ways.

Author Contribution AW and SF contributed to the study conception and design. Material preparation, data collection, and initial analysis were performed by AW, with additional analysis from AF and SF. The manuscript was jointly authored by AW, AF, and SF. All authors approved the final manuscript.

Funding This research was funded by the Commonwealth Department of Health. The content is solely the responsibility of the authors and does not necessarily represent the official views of the Commonwealth Department of Health.

Availability of Data and Material Due to the nature of this research, participants in this study did not agree for their data to be shared publicly, so supporting data are not available.

\section{Declarations}

Ethics Approval This research was conducted with approval from La Trobe University.

Consent to Participate Participants provided informed written consent to participate in this study.

Consent for Publication Participants provided informed written consent to allow their de-identified data to appear in publications.

Competing Interests The authors declare no competing interests.

\section{References}

Ahmed, S. (2004). Collective feelings, or the impressions left by others. Theory, Culture \& Society, (2), 25-42. https://doi.org/10.1177/ 0263276404042133

Angelides, S. (2019). The Fear of Child Sexuality: Young People, Sex, and Agency. University of Chicago Press.

Baker, A. M., Jahn, J. L., Tan, A. S., Katz-Wise, S. L., Viswanath, K., Bishop, R. A., \& Agénor, M. (2020). Sexual health information sources, needs, and preferences of young adult sexual minority 
cisgender women and non-binary individuals assigned female at birth. Sexuality Research \& Social Policy. https://doi.org/10.1007/ s13178-020-00501-6

Barratt, M. J. (2012). The efficacy of interviewing young drug users through online chat. Drug Alcohol Review, 31(4), 566-572. https://doi.org/10.1111/j.1465-3362.2011.00399.x

Bericat, E. (2016). The sociology of emotions: Four decades of progress. Current Sociology, 64(3), 491-513. https://doi.org/10.1177/ 0011392115588355

Birt, L., Scott, S., Cavers, D., Campbell, C., \& Walter, F. (2016). Member checking: A tool to enhance trustworthiness or merely a nod to validation? Qualitative Health Research, 26(13), 802-811. https:// doi.org/10.1177/1049732316654870

Braun, V., \& Clarke, V. (2006) Using thematic analysis in psychology. Qualitative Research in Psychology, 3(2), 77-101. https://doi.org/ 10.1191/1478088706qp063oa

Broucek, F. (1991). Shame and the Self. Guilford Press.

Byron, P., Albury, K., \& Evers, C. (2013). 'It would be weird to have that on Facebook': Young people's use of social media and the risk of sharing sexual health information. Reproductive Health Matters, 21(41), 35-44. https://doi.org/10.1016/S09688080(13)41686-5

Cassidy, C., Bishop, A., Steenbeek, A., Langille, D., Martin-Misener, R., \& Curran, J. (2014). Barriers and enablers to sexual health service use among university students: A qualitative descriptive study using the Theoretical Domains Framework and COM-B model. BMC Health Services Research, 18(1), 581. https://doi. org/10.1186/s12913-018-3379-0

Commonwealth of Australia. (2018). Fourth National Sexually Transmissible Infections Strategy 2018- 2022. Commonwealth of Australia as represented by the Department of Health.

Dolcini, M. M., Warren, J., Towner, S. L., Catania, J. A., \& Harper, G. W. (2015). Information age: Do urban African American youth find sexual health information online? Sexuality Research \& Social Policy, 12, 110-114. https://doi.org/10.1007/s13178-014-0174-5

Fallon, D. (2013). 'They're gonna think it now': Narratives of shame in the sexual health experiences of young people. Sociology, 47(2), 318-332. https://doi.org/10.1177/0038038512441281

Farrugia, A., Waling, A., Pienaar, K., \& Fraser, S. (2021). The be all and end all? Young people, online sexual health information, science and skepticism. Qualitative Health Research, 10497323211003544. https://doi.org/10.1177/10497323211003543

Fields, J. (2008). Risky Lessons: Sex Education and Social Inequality. Rutgers University Press.

Fisher, C., Waling, A., Kerr, L., Bellamy, R, Ezer, P., Mikolajczak, G., \& Lucke, J. (2019a). 6th National Survey of Australian Secondary Students and Sexual Health 2018. Retrieved from National Survey of Australian Secondary Students and Sexual Health's Teen Health website: http://teenhealth.org.au/resources/Reports/ SSASH $\% 202018 \% 20$ National $\% 20$ Report $\% 20-\% 20$ V 10\%20-\% 20web.pdf. Accessed 17 May 2021.

Fisher, C., Mikolajczak, G., Ezer, P., Kerr, L., Bellamy, R., Brown, G., \& Lucke, J. (2019b). Study protocol: 6th National Survey of Australian Secondary Students and Adolescent Sexual Health, 2018. Frontiers in Public Health, 7, 1-12. https://doi.org/10.3389/fpubh. 2019.00217

Flanders, C., Dinh, R., Pragg, L., Dobinson, C., \& Logie, C. (2020). Young sexual minority women's evaluation processes of online and digital sexual health information. Health Communication. Published online ahead of print. https://doi.org/ 10.1080/10410236.2020.1751381

Flick, U. (2011). Concepts of triangulation. In U. Flick (Ed.), Managing Quality in Qualitative Research (pp. 38-54). SAGE Publications.

Fortenberry J. D. (2004). The effects of stigma on genital herpes careseeking behaviours. Herpes: The Journal of the IHMF, 11(1), 8-11. https://europepmc.org/article/med/15115631
Fortenberry, J. D., McFarlane, M., Bleakley, A., Bull, S., Fishbein, M., Grimley, D. M., Malotte, C. K., \& Stoner, B. P. (2002). Relationships of stigma and shame to gonorrhoea and HIV screening. American Journal of Public Health, 92(3), 378-381. https://doi. org/10.2105/ajph.92.3.378

Fraser, S., Fomiatti, R., Moore, D., Seear, K., \& Aitken, C. (2020). Is another relationship possible? Connoisseurship and the doctorpatient relationship for men who consume performance and imageenhancing drugs. Social Science \& Medicine, 246, 112720. https:// doi.org/10.1016/j.socscimed.2019.112720

Fraser, S., Maher, J. M., \& Wright, J. (2010). Between bodies and collectivities: Articulating the action of emotion in obesity epidemic discourse. Social Theory \& Health, 8(2), 192-209. https://doi.org/ 10.1057/sth.2009.28

Fraser, S., Moore, D., Waling, A., \& Farrugia, A. (2021). Making epistemic citizens: Young people and the search for reliable and credible sexual health information. Social Science \& Medicine, 276, 113817. https://doi.org/10.1016/j.socscimed.2021.113817

Gilbert, P. (1998). 'What is shame? Some core issues and controversies.' In P. Gilbert \& B. Andrews (Eds.), Series in Affective Science. Shame: Interpersonal Behaviour, Psychopathology, and Culture (pp. 3-38). Oxford University Press.

Holt, M., Bernard, D., \& Race, K. (2010). Gay men's perceptions of sexually transmissible infections and their experiences of diagnosis: 'Part of the way of life' to feeling 'dirty and ashamed.' Sexual Health, 7, 411-416. https://doi.org/10.1071/SH09117

Jarrett, C., Dadich, A., Robards, F., \& Bennett, D. (2011). 'Adolescence is difficult, some kids are difficult': General practitioner perceptions of working with young people. Australian Journal of Primary Health, 17(1), 54-19. https://doi.org/10.1071/PY10032

Khan, S. A., Alam, F., Rommes, S., \& Rashid, S. F. (2020). Experiencing shame: An affective reading of the sexual and reproductive health and rights classroom in Bangladesh, Sex Education, 20(6), 597-611.https://doi.org/10.1080/14681811.2019. 1707651

Lamb, S. (2013). Just the facts? The separation of sex education from moral education. Educational Theory, 63(5), 443-460. https://doi. org/10.1111/edth.12034

Leahy. D. (2014) Assembling a health[y] subject: Risky and shameful pedagogies in health education. Critical Public Health, 24(2), 171-181. https://doi.org/10.1080/09581596.2013. 871504

Lim, M., Vella, A., Sacks-Davis, R., \& Hellard, M. (2014). Young people's comfort receiving sexual health information via social media and other sources. International Journal of STD and AIDS, 25(14), 1003-1008. https://doi.org/10.1177/0956462414527264

Lindberg, L. D., Maddow-Zimet, I., \& Boonstra, H. (2016). Changes in adolescents' receipt of sex education, 2006-2013. Journal of Adolescent Health, 58(6), 621-627. https://doi.org/10.1016/j. jadohealth.2016.02.004

Litras, A., Latreille, S., \& Temple-Smith, M. (2015). Dr Google, porn and friend-of-a-friend: Where are young men really getting their sexual health information? Sexual Health, 12, 488-549. https:// doi.org/10.1071/SH15055

Magee, J., Bigelow, L., DeHaan, S., \& Mustanski, B. (2012). Sexual health information seeking online: A mixed-methods study among lesbian, gay, bisexual and transgender young people. Health Education and Behaviour, 39(3), 276-289. https://doi.org/10.1177/ 1090198111401384

McBride, E., Tatar, O., Rosberger, Z., Lauren Rockliffe, L., Marlow, L. A. V., Moss-Morris, R., Kaur, N., Wade, K., \& Waller, K. (2020). Emotional response to testing positive for human papillomavirus at cervical cancer screening: A mixed method systematic review with meta-analysis. Health Psychology Review. https://doi.org/10. 1080/17437199.2020.1762106 
Meldrum, R. M., Liamputtong, P., \& Wollersheim, D. (2015). Sexual health knowledge and needs: Young Muslim women in Melbourne. Australia. International Journal of Health Services, 46(1), 124-140.

Patterson, S., Hilton, S., Flowers, P., \& McDaid, L. (2019). What are the barriers and challenges faced by adolescents when searching for sexual health information on the internet? Implications for policy and practice from a qualitative study. Sexually Transmitted Infections, 95(6), 462-467. https://doi.org/10.1136/sextrans-2018-053710

Pound, P., Langford, R., \& Campbell, R. (2016). What do young people think about their school-based sex and relationship education? A qualitative synthesis of young people's views and experiences. BMJ Open, 6(9). https://doi.org/10.1136/bmjopen-2016-011329

Probyn, E. (2004). Teaching bodies: Affects in the classroom. Body \& Society, 10(4), 21-43. https://doi.org/10.1177/1357034X04047854

Probyn, E. (2005). Blush: Faces of Shame. University of Minnesota Press.

Rawson, H. A., \& Liamputtong, P. (2010). Culture and sex education: The acquisition of sexual knowledge for a group of Vietnamese Australian young women. Ethnicity \& Health, 15(4), 343-364. https://doi.org/10.1080/13557851003728264

Ringrose, J. (2016). Postfeminist media panics over girls' sexualisation: Implications for UK sex and relationships guidance and curriculum. In V. Sunderam \& H. Sauntson (Eds.), Global Perspectives and Key Debates in Sex and Relationships Education: Addressing Issues of Gender, Sexuality, Plurality and Power (pp. 30-47). Palgrave Macmillan.

Roberts, J. H., Crosland, A., \& Fulton, J. (2013). 'I think this is maybe our Achilles heel...' Exploring GPs' responses to young people presenting with emotional distress in general practice: A qualitative study. BMJ Open, 3, e002927.

Saunders, B., Sim, J., Kingstone, T., Baker, S., Waterfield, J., Bartlam, B., Burroughs, H., \& Jinks, C. (2018). Saturation in qualitative research: Exploring its conceptualisation and operationalisation. Quality \& Quantity, 52(4), 1893-1907. https://doi.org/10.1007/ s11135-017-0574-8

Sayles, J. N., Wong, M. D., Kinsler, J. J., Martins, D., \& Cunningham, W. E. (2009). The association of stigma with self-reported access to medical care and antiretroviral therapy adherence in persons living with HIV/AIDS. Journal of General Internal Medicine, 24(10), 1101-1108. https://doi.org/10.1007/s11606-009-1068-8

Simon, L., \& Daneback, K. (2013). Adolescents' use of the internet for sex education: A thematic and critical review of the literature. International Journal of Sexual Health, 25(4), 305-319. https:// doi.org/10.1080/19317611.2013.823899
Shapka, J. D., Domene, J. F., Khan, S., \& Yang, L. M. (2016). Online versus in-person interviews with adolescents: An exploration of data equivalence. Computers in Human Behaviour, 58, 361-367. https://doi.org/10.1016/j.chb.2016.01.016

Shoveller, J. A., \& Johnson, J. L. (2006). Risky groups, risky behaviour, and risky persons: Dominating discourses on youth sexual health. Critical Public Health, 16(1), 47-60. https://doi.org/10. 1080/09581590600680621

Tupper, K. W. (2014). Sex, drugs and the honour roll: The perennial challenges of addressing moral purity issues in schools. Critical Public Health, 24(2), 115-131. https://doi.org/10.1080/09581596. 2013.862517

United Nations Educational, Scientific and Cultural Organisation (UNESCO). (2021). Comprehensive Sexuality Education: A Foundation for Life and Love Campaign. [online]. https://en.unesco.org/ themes/education-health-and-well-being/cse-campaign. Accessed 22 Jun 2021.

Waling, A., Bellamy, R., Ezer, P., Kerr, L., Lucke, J., \& Fisher, C. (2020a). 'It's kinda bad, honestly.': Australian students' experiences of relationships and sexuality education. Health Education Research. Published online ahead of print. https://doi.org/10.1093/ her/cyaa032

Waling, A., Fisher, C., Ezer, P., Bellamy, R., Kerr, L., \& Lucke, J. (2020b). 'Please teach students that sex is a healthy part of growing up.': Australian students' desires for sexuality and relationships education. Sexuality Research and Social Policy. Published online ahead of print. https://doi.org/10.1007/s13178-020-00516-Z

Waling, A., Fraser, S., \& Fisher, C. (2020c). Young People and Sources of Sexual Health Information (Monograph No. 121). ARCSHS, La Trobe University. https://www.latrobe.edu.au/_data/assets/pdf_ file/0010/1156843/Sources-of-Sexual-Health-Information-.pdf

Waller, J., Marlow, L. A. V., \& Wardle, J. (2007). The association between knowledge of HPV and feelings of stigma, shame and anxiety. Sexually Transmitted Infections, 83(2), 155-159. https:// doi.org/10.1136/sti.2006.023333

World Health Organisation. (2006). Sexual and Reproductive Health and Research Including the Special Programme HRP. WHO. www.who.int/teams/sexual-and-reproductive-health-andresearch/key-areas-of-work/sexual-health/defining-sexual-health. Accessed 15 Jan 2021.

Publisher's Note Springer Nature remains neutral with regard to jurisdictional claims in published maps and institutional affiliations. 